\title{
Quality of Life and Health Status among those receiving Renal Replacement Therapy in Trinidad and Tobago. West Indies.
}

Sharlene Maria Sanchez ( $\sim$ sanchezsharlene32@yahoo.com )

Adventist University of Health Sciences Robert Arthur Williams Library https://orcid.org/0000-0003$1512-4818$

\section{Surujpal Teelucksingh}

The University of the West Indies at Saint Augustine

\section{Ronan Ali}

The University of the West Indies at Saint Augustine

\section{Henry Bailey}

The University of the West Indies at Saint Augustine

\section{George Legall}

The University of the West Indies at Saint Augustine

\section{Research article}

Keywords: Renal replacement therapy, quality of life, EQ-5D-3L, KDQOL-36

Posted Date: April 16th, 2020

DOl: https://doi.org/10.21203/rs.3.rs-19194/v1

License: (c) (1) This work is licensed under a Creative Commons Attribution 4.0 International License. Read Full License 


\section{Abstract}

Background A cross sectional study was conducted over a 1-year period in order to evaluate quality of life and health state for patients receiving renal replacement therapy in a resource constrained Caribbean island of Trinidad and Tobago. Methods Five hundred and thirty patients were enlisted in the study. For those who had received renal transplants $(n=100)$ and for those on peritoneal dialysis $(n=80)$, all were included. Among the 1000-odd patients who were receiving haemodialysis 350 were studied using convenience sampling. To be included, one had to be on renal replacement therapy for 3 months or more and at least 18 years of age. The Kidney Disease Quality of Life (KDQOL-36) and the EuroQol (EQ-5D-3L) instruments were administered after demographic data were collected. Transplant recipients were further evaluated with the Kidney Transplant Questionnaire (KTQ). Inferential analysis of data included 95\% confidence intervals, hypothesis testing, multiple regression and analysis of variance. SPSS24, STATA14 and MINITAB18 were used. Results Of the 530 patients, $52.5 \%$ were male and $37.5 \%$ were in the $56-65$ years age group. Hypertension (68.9\%) and type 2 diabetes mellitus (50.5\%) were reported as the main causes of kidney disease. The KDQOL-36 domain scores and significantly associated variables included modality of renal replacement $(p=0.000)$, age $(p=0.001)$, Charlson's Comorbidity Index $(p=0.001)$, income $(p=0.000)$ and employment status $(p=0.000)$. Transplant patients performed the best in the KDQOL-36. The mean visual analogue scale and index scores from the EQ-5D-3L were highest among renal transplant recipients $(p=0.000)$. Conclusion Renal transplant recipients enjoy the best quality of life and health state among patients on renal replacement therapy in Trinidad and Tobago.

\section{Background}

The measurement of quality of life in patients with chronic disease is a complex entity that encompasses state of health, impact of disease, emotional factors and social support. Chronic kidney disease with its associated comorbidities and complications is a great challenge for physicians, patients and caregivers. Renal replacement therapy for end stage renal disease includes haemodialysis, peritoneal dialysis and renal transplantation. Patients with an improved quality of life have better treatment outcomes and decreased morbidity and mortality. ${ }^{1-6}$ This study is the first in the Caribbean to evaluate the quality of life and health state associated with renal replacement therapy. In other settings, the determinants of quality of life of patients on renal replacement therapy are different. ${ }^{7-15}$

An earlier small study in Trinidad had shown that $18 \%$ of asymptomatic patients had evidence for stage 3 chronic kidney disease. ${ }^{16}$ Data from the Caribbean showed that diabetes and hypertension were the major contributors to this burden. ${ }^{17}$ Of the modalities of renal replacement, renal transplantations offer the best survival and quality of life with survival rates in Trinidad of $91.46 \%$ (SE 0.04), 89.51\% (SE 0.04) and $86.31 \%$ (SE 0.05) for 1 year, 2 years and 3 years respectively. ${ }^{18}$ However, the decision and choice of modality of renal replacement therapy are influenced by financial, social and medical factors. Thus, in Trinidad and Tobago, government funding for haemodialysis is dependent on a patient's present economic circumstances, which is assessed by the state. On the other hand, peritoneal dialysis is offered 
to all patients once they are deemed suitable for this therapy. The attending nephrologist determines referrals to the renal transplantation unit and criteria must be fulfilled to be considered for transplantation.

The aim of this study is to investigate differences in health related quality of life for patients receiving different types of renal replacement therapy to better allocate resources in the future. Findings will also aid physicians in guiding choices of therapy tailored to individual circumstances and educate patients in their decision making when considering modality of renal replacement therapy.

\section{Methods}

\section{Study description}

Patients receiving renal replacement therapy in Trinidad and Tobago start dialysis or receive a renal transplant. Dialysis options include peritoneal dialysis and haemodialysis. The Government of Trinidad and Tobago funds this service. Haemodialysis and peritoneal dialysis are offered at the public health facilities with no user fees. The Ministry of Health through an external patient programme funds most patients at privately-operated haemodialysis centres. Patients access the central totally governmentfunded transplant unit via referrals from specialist nephrologists and such candidates are considered for living or deceased donor transplantations.

This was a cross sectional study that sampled patients on all forms of renal replacement therapy. The survey period ran for just over 1 year from the $1^{\text {st }}$ October 2015 to the 31 st October 2016.

\section{Inclusion and exclusion criteria}

Inclusion criteria had been patients receiving a transplant or on dialysis for 3 months or more and at least 18 years of age. Studies had shown that this period is essential for adaptation to activities of daily living and return to regular functioning. ${ }^{6,9-10}$

Exclusion criteria had been those on renal replacement therapy for less than 3 months and persons less than 18 years of age. Furthermore, persons hospitalized within 4 weeks from administration of the questionnaires were excluded from this study in keeping with the recommendation of the developers of the KDQOL (Kidney Disease Quality of Life) instrument used to obtain data to assess quality of life.

\section{Sample size}

Since there is no formula determining sample sizes for non-random sampling the formula for the size of simple random samples was used to determine the number of participants that would be needed for the study. 
$n=\frac{N Z_{\frac{0.05}{2}}^{2} p(1-p)}{(N-1) d^{2}+Z_{\frac{0.05}{2}}^{2} p(1-p)}$

In this formula $\mathrm{N}=1383$ was the approximate number of patients on renal replacement therapy in Trinidad and Tobago at the time of the study, $\frac{Z_{0.05}^{2}=1.96}{2}$, is the standard normal distribution two-tailed 5\% value and $d=0.05$ is the margin of error. The estimated minimum sample size was 384 patients. These included at least 262 haemodialysis patients from private centres and 61 from public centres, 35 transplant recipients and 26 patients on peritoneal dialysis using approximate number of patients on each therapy. This study had a sample size of 530, constituting the following: 100 transplant patients, 80 peritoneal dialysis patients, 264 private haemodialysis patients and 86 public haemodialysis patient.

All peritoneal dialysis and renal transplant patients meeting inclusion criteria were investigated. Convenience sampling was used to select haemodialysis participants form both public and private institutions. Stratified random sampling was done among 16 private facilities for haemodialysis. Geographical locations using distributions within health facilities were used to obtain ratios for stratified random sampling. These were the North Central, North West, and South West regional health facilities. The 16 private haemodialysis centres were located within these regional health authorities. These private facilities were distributed in a 1:1:2 ratio respectively. Thirteen haemodialysis centres that included all the public centres and 8 private centres were studied.

\section{Questionnaires}

The International Standard Classification of Occupations of the United Nations ${ }^{19}$, the World Health Organization Global Database on Body Mass Index ${ }^{20}$ and the International Statistical Classification of Diseases and Related Health Problems $10^{\text {th }}$ Revision ${ }^{21}$ were used to classify occupation, body mass index and diseases respectively in the demographics questionnaire. The demographics questionnaire also included information from participants on age, gender, ethnicity, comorbidities, aetiology of kidney disease, mode of renal replacement therapy, access type for haemodialysis, smoking and alcohol consumption. For the obese category, persons of Asian $\left(25 \mathrm{~kg} / \mathrm{m}^{2}\right)$ and Afro-Caribbean descents $\left(27 \mathrm{~kg} / \mathrm{m}^{2}\right)$ were classified based on a prospective study that investigated ethnic groups. ${ }^{22}$ Charlson's Comorbidity Index (CCl) estimates 10 year survival in patients with multiple comorbidities. ${ }^{23} \mathrm{~A}$ higher score indicates a lower percentage estimated 10 year survival. $\mathrm{CCl}$ and mean quality of life scores were calculated.

The KDQOL-36 is a 36-item questionnaire that investigates quality of life. This was developed for patients with chronic renal disease and dialysis patients. It has been used for the evaluation of transplant patients and is valid and reliable in many populations. ${ }^{24-28}$ The domain components include a physical and mental subset, burden of illness, symptoms and effect of disease on life. 
The EuroQol (EQ-5D-3L) self-reported health instrument was also included. The EQ-5D-3L classification system has five domains: mobility, self-care, ability to perform usual activities, pain/discomfort and anxiety/depression. Each dimension is scored from 1 to 3 with 1 representing ' no problems', 2 representing 'moderate problems', and 3 representing 'extreme problems'. The EQ-5D-3L self reported health instrument also includes a visual analogue scale on which a respondent provides their selfassessed health rating on a 0 (worst health imaginable) to 100 (best health imaginable) scale. The EQ$5 \mathrm{D}-3 \mathrm{~L}$ value set for Trinidad and Tobago was used to determine utility values for patients on all modalities of renal replacement therapy. ${ }^{29}$ Trinidad and Tobago EQ-5D-3L population norms from a forthcoming study were used to compare EQ-5D-3L results for the patients on renal replacement therapy.

Transplant recipients were further analysed with the Kidney Transplant Questionnaire (KTQ). The KTQ is a quality of life instrument designed for transplant patients. The responses were analysed with a 7-point Likert scale where patients with a better quality of life had higher scores. ${ }^{10}$ This questionnaire was also validated for renal transplant recipients in a Trinidad and Tobago population. It is valid and reliable in other populations. ${ }^{9,}, 30$

\section{Data collection and informed consent}

Preparation for fieldwork included piloting and editing the questionnaire, creating a field manual to guide the data collection process and a coding dictionary to facilitate data to be used for data coding (qualitative data) prior to data entry. Prospective data collectors were trained in the use of the field manual. Data was regularly tested for high inter-collector reliability (Cohen's kappa) and high agreement with a gold standard. All persons in this study provided informed consent in writing. Participants were thoroughly counselled on the undertakings of the research. Questionnaires were administered in an interview-based format and confidentiality was maintained.

\section{Ethical approval}

All permissions were obtained for public and private institutions. The ethics committees from the corresponding regional health facilities: North Central, North West, South West, Eastern and Tobago gave their approvals. The University of the West Indies ethics committee granted approval for this research.

\section{Data Entry and Analysis}

The statistics software Statistical Package for the Social Sciences (SPSS) version 24 and Microsoft EXCEL was used for data entry and editing prior to data analysis. Preliminary computations included calculating a $\mathrm{CCl}$ for each patient. This index categorizes patients according to their probability of surviving different diseases during the 10-year period subsequent to the date on which the index was computed. ${ }^{23}$ The lower the index the greater the probability of survival. Figure 1 shows the probability associated with each index value. 
Subsequently SPSS version 24, MINITAB version 18 and STATA version 14 were used for both descriptive and inferential data analysis. Descriptive methods included frequency and percentage distribution tables, and summary statistics. Inferential methods included $95 \%$ confidence intervals, hypothesis testing at the $5 \%$ level of significance, multiple regression analysis and analysis of variance.

Reliability of the KDQOL questionnaire and the KTQ in this population was tested with Cronbach's alpha. The validity of these questionnaires were analysed with Pearson's correlation. (2 tailed)

\section{Results}

\section{Baseline characteristics}

A total of $530(97.1 \%)$ of the 546 patients selected participated in the study and their characteristics are shown in Table 1. The 16 patients who declined were on haemodialysis. Figure 2 shows the age groups of the patients.

Table 1: Characteristics of patients on renal replacement therapy 


\begin{tabular}{|c|c|c|c|c|}
\hline Characteristic & $\begin{array}{l}\text { All modalities/ } \\
\text { Percent (\%) patients } \\
\mathrm{N}=530\end{array}$ & $\begin{array}{l}\text { Haemodialysis/ } \\
\text { Percent (\%) } \\
\text { patients } \\
\mathrm{H}=350\end{array}$ & $\begin{array}{l}\text { Peritoneal } \\
\text { Dialysis/ } \\
\text { Percent (\%) } \\
\text { patients } \\
\mathrm{P}=80\end{array}$ & $\begin{array}{l}\text { Renal } \\
\text { Transplant/ } \\
\text { Percent (\%) } \\
\text { patients } \\
\mathrm{T}=100\end{array}$ \\
\hline \multicolumn{5}{|l|}{ Sex } \\
\hline Male & 52.50 & 52.30 & 46.30 & 58.00 \\
\hline Female & 47.50 & 47.70 & 53.70 & 42.00 \\
\hline \multicolumn{5}{|l|}{ Ethnicity } \\
\hline Indo Trinidadian & 51.50 & 52.50 & 53.50 & 58.00 \\
\hline Afro Trinidadian & 37.50 & 38.50 & 36.50 & 32.00 \\
\hline Mixed & 10.00 & 7.50 & 9.00 & 9.00 \\
\hline Other & 1.00 & 1.50 & 1.00 & 1.00 \\
\hline \multicolumn{5}{|l|}{ Income/month } \\
\hline$\leq \$ 1000 \mathrm{TT}$ & 46.98 & 58.51 & 32.50 & 27.00 \\
\hline $\begin{array}{l}>\$ 1000 \mathrm{TT} \\
\leq \$ 4000 \mathrm{TT}\end{array}$ & 12.83 & 15.37 & 11.25 & 1.00 \\
\hline $\begin{array}{l}>\$ 4000 \mathrm{TT} \\
\leq \$ 8000 \mathrm{TT}\end{array}$ & 30.57 & 24.51 & 37.50 & 42.00 \\
\hline $\begin{array}{l}>\$ 8000 \mathrm{TT} \\
\leq 12000 \mathrm{TT}\end{array}$ & 8.68 & 1.77 & 18.75 & 25.00 \\
\hline$>12000 \mathrm{TT}$ & 0.94 & 0.00 & 0.00 & 5.00 \\
\hline \multicolumn{5}{|l|}{ Occupation } \\
\hline Managers & 4.15 & 2.57 & 1.25 & 12.00 \\
\hline Professionals & 7.92 & 2.85 & 11.25 & 23.00 \\
\hline Technicians and associate professionals & 1.70 & 0.29 & 1.25 & 7.00 \\
\hline Clerical support workers & 3.40 & 1.43 & 6.25 & 8.00 \\
\hline service and sales workers & 7.55 & 8.57 & 6.25 & 5.00 \\
\hline $\begin{array}{l}\text { Skilled agricultural forestry and fishery } \\
\text { workers } \\
\text { Craft and related trade worker }\end{array}$ & 0.38 & 0.28 & 0.00 & 1.00 \\
\hline $\begin{array}{l}\text { Plant and machine operators and } \\
\text { assemblers }\end{array}$ & 4.91 & 2.00 & 6.25 & 14.00 \\
\hline Elementary occupations & 3.58 & 1.71 & 13.75 & 2.00 \\
\hline
\end{tabular}




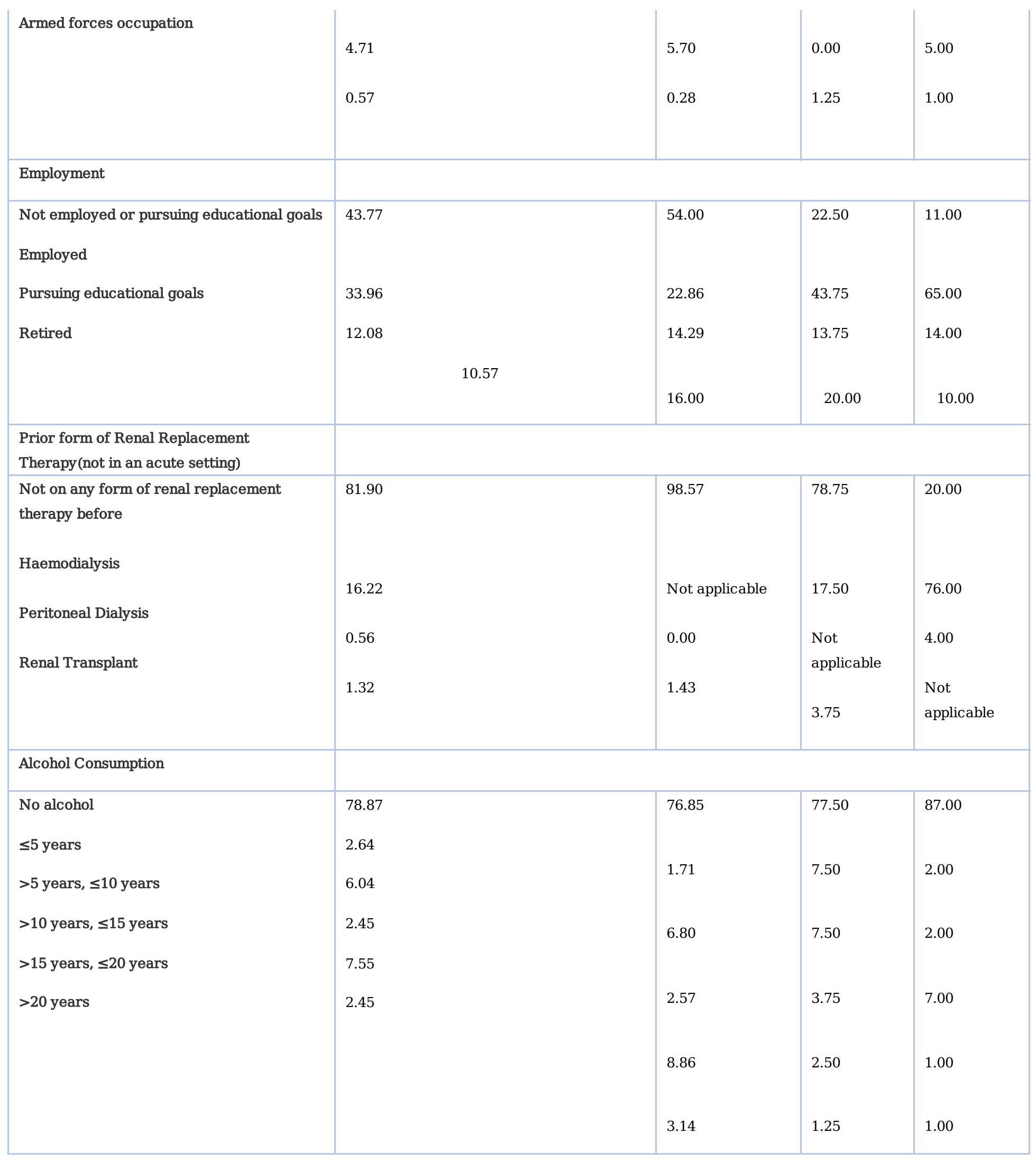

Underweight patients were predominantly on peritoneal dialysis and the prevalence of obesity was greater among haemodialysis patients (Figure 3). Patients on renal replacement therapy reported hypertension and type 2 diabetes mellitus as the main causes of chronic kidney disease (Figure 4). In 
$84 \%$ of persons, the diagnosis of chronic kidney disease was made when patients required renal replacement therapy.

Thirty three percent of patients on haemodialysis had an arteriovenous fistula or graft (AVF/G) as their primary access type. Almost half of the patients with permanent catheters were managed for catheter related blood stream infections. Infective endocarditis was reported in $15 \%$ of those patients. With respect to comorbidities, all patients with a $\mathrm{CCl} \geq 6$ were on haemodialysis. No transplant or peritoneal dialysis patients had a $\mathrm{CCl} \geq 6$. These patients constituted $15 \%$ of the total number of patients on haemodialysis.

\section{KDQOL-36 scores and variables studied}

The KDQOL total and domain scores were calculated as percentages. Table 2 shows mean scores and mode of renal replacement. Analysis of variance and multivariate regression analysis in table 3 demonstrated significance for domain scores and modality $(p=0.000)$, age $(p=0.001), C C l(p=0.001)$, income $(p=0.000)$, employment status $(p=0.000)$ and alcohol consumption $(p=0.019)$. Tukey range test, Post hoc test and robust test of means of total scores and domain scores of patients were done. Table 4 shows that patients on haemodialysis with an AVF/G reported higher mean KDQOL scores than those with haemodialysis catheters $(p=0.000)$.

Table 2: Mean scores and modality of renal replacement therapy

\begin{tabular}{|l|l|l|l|l|l|l|l|}
\hline Mode Of Therapy & Measure & Total Score/\% & Physical/\% & Mental /\% & Symptoms/\% & Burden/\% & Effect On Life/\% \\
\hline $\begin{array}{l}\text { Hemodialysis } \\
\text { N=350 }\end{array}$ & Mean & 53.87 & 51.50 & 62.96 & 53.43 & 47.69 & 52.90 \\
\cline { 2 - 8 } & Std. Deviation & 23.47 & 22.30 & 21.26 & 28.37 & 23.06 & 26.89 \\
\hline $\begin{array}{l}\text { Peritoneal Dialysis } \\
\text { N=80 }\end{array}$ & Mean & 85.26 & 75.00 & 82.17 & 92.52 & 70.19 & 87.28 \\
\cline { 2 - 8 } & Std. Deviation & 10.61 & 21.95 & 15.57 & 9.38 & 24.25 & 12.35 \\
\hline $\begin{array}{l}\text { Renal Transplant } \\
\text { N=100 }\end{array}$ & Mean & 98.10 & 98.10 & 96.70 & 98.10 & 98.25 & 98.80 \\
\cline { 2 - 8 } & Std. Deviation & 4.20 & 4.70 & 7.70 & 4.80 & 5.56 & 3.43 \\
\hline
\end{tabular}

Table 3: Analysis of variance for KDQOL-36 and variables studied 


\begin{tabular}{|c|c|c|c|c|}
\hline \multirow[t]{2}{*}{ Constant } & \multirow[t]{2}{*}{ Std Error } & \multicolumn{2}{|c|}{ 95\% Confidence Interval } & \multirow[t]{2}{*}{ Sig. } \\
\hline & & Lower & Upper & \\
\hline Age & 0.10 & 0.07 & 0.48 & 0.00 \\
\hline Mode of therapy & 1.78 & 25.83 & 32.81 & 0.00 \\
\hline Charlson's Comorbidity Index & 0.97 & -4.41 & -0.58 & 0.00 \\
\hline Income & 0.58 & 4.37 & 6.64 & 0.00 \\
\hline Employment status & 1.00 & 1.60 & 5.57 & 0.00 \\
\hline Alcohol consumption & 0.68 & 1.14 & 3.83 & 0.02 \\
\hline
\end{tabular}

Table 4: Mean scores of patients on haemodialysis and primary access

\begin{tabular}{|c|c|c|c|c|c|c|c|}
\hline Access Type & Measure & Total Score/\% & Physical/\% & Mental/\% & Symptoms/\% & Burden/\% & Effect On Life/\% \\
\hline \multirow{2}{*}{$\begin{array}{l}\text { Av Fistula } \\
N=108\end{array}$} & Mean & 76.62 & 65.40 & 78.57 & 79.65 & 69.56 & 77.58 \\
\hline & Std. Deviation & 19.23 & 16.10 & 15.96 & 23.67 & 20.25 & 24.58 \\
\hline $\begin{array}{l}\text { Av Graft } \\
N=9\end{array}$ & Std. Deviation & 25.07 & 11.75 & 15.65 & 30.27 & 33.75 & 28.73 \\
\hline \multirow{2}{*}{$\begin{array}{l}\text { Permanent Catheter } \\
\mathrm{N}=229\end{array}$} & Mean & 42.77 & 42.10 & 55.74 & 40.68 & 36.63 & 40.68 \\
\hline & Std. Deviation & 15.94 & 17.80 & 19.74 & 20.30 & 14.25 & 18.00 \\
\hline \multirow{2}{*}{$\begin{array}{l}\text { Other } \\
\mathrm{N}=4\end{array}$} & Mean & 31.45 & 32.50 & 45.65 & 23.75 & 6.25 & 33.75 \\
\hline & Std. Deviation & 6.59 & 8.65 & 12.52 & 3.43 & 7.88 & 10.10 \\
\hline
\end{tabular}

\section{Transplant patients and the KTQ}

The KTQ uses a Likert scale where higher scores indicate a better quality of life. The total score is 175 and the lowest is 25 . Table 5 shows the KTQ subscales and the percentage of transplant recipients obtaining the maximum in each subscale.

Table 5: Transplant patients obtaining the maximum score in each subscale in the KTQ 


\begin{tabular}{|l|l|}
\hline Dimension & Transplant recipients obtaining maximum score/\% \\
\hline Physical symptoms & 82 \\
\hline Fatigue & 74 \\
\hline Uncertainty/fear & 79 \\
\hline Appearance & 85 \\
\hline Emotional & 70 \\
\hline
\end{tabular}

\section{EQ-5D-3L results}

The mean VAS and mean index values seen in Table 6 were best among the transplant group followed by peritoneal dialysis then haemodialysis $(p=0.000)$. Table 7 shows that transplant patients perform better than haemodialysis patients based on both the EQ-VAS and index values. Additional file 1, supplementary table 1 shows the EQ-5D-3L health states that were observed for the 3 groups in this study. Four EQ-5D-3L states were observed among transplant patients. Ninety five percent of the transplant recipients were in the full health state (11111). None of the transplant recipients reported level three on any of the EQ-5D dimensions. In comparison to population norms for age and gender in Trinidad and Tobago, the health state profile for transplant patients was better than the normal population.

Table 6 shows the EQ-VAS and index values for the three groups. On both measures, the transplant group has the highest values and the haemodialysis group had the lowest values.

Table 6: Mean VAS and index values using EQ-5D-3L for patients on renal replacement

\begin{tabular}{|c|c|c|c|}
\hline \multirow[t]{2}{*}{ Measures } & \multicolumn{3}{|l|}{ Mode of Therapy } \\
\hline & Haemodialysis & Peritoneal Dialysis & Transplant \\
\hline Mean VAS & 62.00 & 79.13 & 88.25 \\
\hline Std Error & 0.74 & 1.46 & 1.19 \\
\hline 95\% Confidence Interval & 60.54-63.46 & 76.26-81.99 & $85.90-90.60$ \\
\hline Mean Index & 0.78 & 0.90 & 0.99 \\
\hline Std Error & 0.01 & 0.02 & 0.00 \\
\hline 95\% Confidence Interval & $0.76-0.80$ & $0.87-0.93$ & 0.99-0.99 \\
\hline
\end{tabular}

VAS: Visual Analogue Scale 
Table 7 shows the results of ordinary least squares regression model for EQ-VAS and EQ-5D index values with controls for age and gender. Transplant is used as the reference category with dummy variables for peritoneal dialysis and haemodialysis. The coefficients for peritoneal dialysis and haemodialysis in these models are $-8.63,-25.74$ and $-0.08,-0.20$ for EQ-VAS and EQ-5D respectively.

Table 7: Visual analogue scale and index values using ordinary least squares regression and robust standard errors of transplant recipients compared to patients on haemodialysis and peritoneal dialysis

\begin{tabular}{|c|c|c|c|c|c|}
\hline \multirow[t]{2}{*}{ VAS } & \multirow[t]{2}{*}{ Coefficient } & \multirow{2}{*}{$\begin{array}{l}\text { Standard } \\
\text { Error }\end{array}$} & \multirow[t]{2}{*}{$\mathrm{P}>\mathrm{t}$} & \multicolumn{2}{|c|}{ 95\% Confidence Interval } \\
\hline & & & & Lower & Upper \\
\hline Age & -0.53 & 0.43 & 0.22 & -1.36 & 0.31 \\
\hline Gender & -0.41 & 1.17 & 0.73 & -2.71 & 1.89 \\
\hline $\mathrm{PD}$ & -8.63 & 2.05 & 0.00 & -12.66 & -4.59 \\
\hline HD & -25.74 & 1.58 & 0.00 & -28.84 & -22.65 \\
\hline Constant & 90.61 & 2.60 & 0.00 & 85.51 & 95.7 \\
\hline \multirow[t]{2}{*}{ Index } & \multirow[t]{2}{*}{ Coefficient } & \multirow{2}{*}{$\begin{array}{l}\text { Standard } \\
\text { Error }\end{array}$} & \multirow[t]{2}{*}{$\mathrm{P}>\mathrm{t}$} & \multicolumn{2}{|c|}{ 95\% Confidence Interval } \\
\hline & & & & Lower & Upper \\
\hline Age & -0.01 & 0.00 & 0.01 & -0.02 & -0.00 \\
\hline Gender & -0.00 & 0.01 & 0.93 & -0.03 & 0.02 \\
\hline $\mathrm{PD}$ & -0.08 & 0.02 & 0.00 & -0.13 & -0.04 \\
\hline HD & -0.20 & 0.02 & 0.00 & -0.24 & -0.17 \\
\hline Constant & 1.04 & 0.03 & 0.00 & 0.97 & 1.09 \\
\hline
\end{tabular}

PD-Peritoneal dialysis, HD-Haemodialysis

\section{Validity and reliability of questionnaires}

The KDQOL and KTQ are valid and reliable in this population. Pearson's correlation (2 tailed) was significant at a 0.01 level. All questions were valid $(p=0.000)$. Cronbach's alpha values were 0.988 and 0.999 for the KDQOL-36 and KTQ respectively. (Table 8) 


\begin{tabular}{|l|l|l|}
\hline Questionnaire & Cronbach's alpha & Number of Items \\
\hline KDQOL-Kidney Disease Quality of Life & 0.988 & 36 \\
Your Health subset (physical and mental component) & & 12 \\
Your Kidney Disease subset (symptom and burden of disease component) & 0.940 & 16 \\
Effects of Kidney Disease subset & 0.940 & \\
\hline KTQ-Kidney Transplant Questionnaire & 0.979 & 8 \\
\hline Physical symptoms & 0.999 & 25 \\
\hline $\begin{array}{l}\text { Fatigue } \\
\text { Uncertainty/fear }\end{array}$ & 0.999 & 6 \\
\hline Appearance & 0.999 & 6 \\
\hline Emotional & 0.999 & 699 \\
\hline
\end{tabular}

\section{Discussion}

\section{Overview}

Quality of life is a difficult and complex construct to measure that involves the interplay of numerous factors and extends into all aspects of an individual's functioning. Wilson and Cleary provide a model that starts at a cellular level and progresses to the individual interacting with society. ${ }^{31}$ Quality of life not only encompasses genetics and the environment but also includes social, cultural, economic and psychological measurements. In assessing the success of therapy, quality of life and state of health has been used throughout the years as indicators of treatment outcome and subsequently can be employed to evaluate the cost effectiveness of therapies.

In this population, about $90 \%$ of patients on renal replacement are on dialysis and two thirds of the haemodialysis patients have permanent catheters as their primary access type. These findings emphasize the importance of this study in a Caribbean population and the impact of the factors affecting quality of life. Robinson et al has shown differences in the patient population on renal replacement therapy across the continents. ${ }^{32}$ In particular, it was seen that most of the patients in Japan on 
haemodialysis use an arteriovenous fistula. ${ }^{32}$ The majority of patients around the globe have renal transplants. $^{32}$

\section{Biological factors}

\section{Mode of renal replacement therapy}

In 1985, Evans and colleagues measured the quality of life of patients undergoing dialysis and transplantation. They found that $79.1 \%$ of transplant patients were able to function at nearly normal levels compared to between $47.5 \%$ and $59.1 \%$ of dialysis patients depending on the type of dialysis. ${ }^{33}$ In this study it was found that patients who received renal transplants had better quality of life scores compared with dialysis patients. (Figure 5, Table 2) Peritoneal dialysis patients performed better than haemodialysis patients. Renal transplant patients also achieved higher scores in the disease specific domains of the KDQOL questionnaire than dialysis patients. In the haemodialysis and peritoneal dialysis groups, the burden of kidney disease was the greatest challenge for patients. (Table 2) This suggests that transplantation is the most physiological as a form of renal replacement. In the transplant group, the mental domain subset had the lowest score compared to other domains of the KDQOL. The KTQ used for transplant patients further demonstrated that quality of life of transplant patients was high. This shows that in patients with end stage renal disease, the option of dialysis is still a great challenge for patients and physicians and institution of measures to improve quality of life for patients on peritoneal dialysis and haemodialysis is necessary. This study can guide decision makers with the potential solutions to assist with disease burden. Patients on haemodialysis with an AVF/G have better quality of life scores than those with a haemodialysis catheter because of fewer complications. Policy guidelines and support networks can therefore be improved for prompt referral and early surgery for an AVF/G when choosing haemodialysis.

Most studies have shown that renal transplant recipients have better quality of life scores. ${ }^{1-2,8,12-14} \mathrm{~A}$ meta-analysis done on the quality of life of patients on renal replacement therapy concluded that haemodialysis and peritoneal dialysis patients tend to have an inferior quality of life when compared to transplant recipients. ${ }^{12}$ Quality of life was worse for haemodialysis compared to peritoneal dialysis patients. ${ }^{12,15}$ This was also found in this study. (Table 2) Peritoneal dialysis requires a patient to have good social support and adequate facilities in the home environment to perform the procedure on a daily basis. The medical social worker plays an integral role in deciding candidacy. Health care workers also meticulously train patients and their families regularly.

In the EQ-5D-3L health state, transplant recipients actually performed better than the age and gender adjusted population norms for Trinidad and Tobago. Renal transplant recipients performed the best on the VAS and index values. Ninety five percent of transplant recipients were in state 11111, the best state of health. The distribution of health states, VAS and index values further support renal transplantation being the most physiologically similar to normal functioning. Additional file 2 , supplementary figure 1 shows that transplant recipients reported less problems than the normal population. This finding can be 
investigated in a future study. The ordinary least squares regression model in Table 7 shows that by placing patients on peritoneal dialysis or having a renal transplantation drastically improves quality of life for the number of years on renal replacement therapy. The decrement in quality of life is greatest in the haemodialysis group. There is a marked difference of 17 VAS points and 0.12 utility for patients on haemodialysis compared to peritoneal dialysis. A transition from peritoneal dialysis to haemodialysis would impact greatly on quality of life for suitable candidates.

Renal transplant recipients were also maintained on their therapy for longer periods than persons on other forms of therapy. Using a period of 5 years on renal replacement therapy, $8 \%$ of patients were on haemodialysis while about one third of all transplant recipients had functioning grafts. These findings can be due to a number of reasons including comorbidities, age and type of access among this group, which will influence mortality. Renal transplantation when compared to other forms of renal replacement therapy is associated with fewer hospitalizations and death influencing the cost effectiveness of this modality around the world. ${ }^{34-35}$

Renal transplantation is the most physiologically similar to one's body as a mode of renal replacement therapy. Among transplant recipients, immunologic similarity can further be assessed with haplotype match between donor and recipient. Transplantation is also the least time consuming method of all modalities. Haemodialysis patients have approximately 3 sessions of haemodialysis per week, while peritoneal dialysis patients undergo dialysis sessions at their home. It is therefore expected that renal transplantation should lead to a better quality of life.

\section{Lifestyle diseases}

During this study, it was shown that almost three quarter of patients on renal replacement therapy in Trinidad and Tobago were diabetic and/or hypertensive. When patients with other stages of chronic kidney disease are taken into consideration, these numbers may be larger for this population. Over $80 \%$ of patients were diagnosed with kidney disease when renal replacement was necessary. This finding exposes the inadequacies of screening and the necessity for better strategies for preventing and treating lifestyle diseases in our setting.

Patients on haemodialysis also had more comorbidities than patients on other types of renal replacement suggesting that haemodialysis is associated with more complications. A CCI $\geq 6$ equivalent to a 10 -year survival probability of 0 was found only among the haemodialysis group.

\section{Alcohol use}

It has been shown that smoking and alcohol cessation in patients with renal disease may lead to a better quality of life. Francisco et al showed that patients who never smoked cigarettes or did not consume alcohol had higher quality of life scores. ${ }^{36}$ Patients with a higher quality of life may have fewer stressors and engage less frequently in these detrimental habits. In this study, patients who consumed 5 units or less of alcohol weekly had better quality of life scores. 


\section{AVF/G for haemodialysis}

Patients with an AVF/G had better mean KDQOL-36 scores when compared to patients with permanent catheters. (Table 4) It has been shown that this access type is not only cost efficient but offers a better quality of life for patients because of fewer complications than a permanent catheter. 37,38

Patients who were on haemodialysis for a longer time possibly were able to obtain an AVF/G before others because of the length of time in the public health care system. Improved quality of life in the older dialysis patients was likely due to the presence of an AVF/G.

\section{Adiposity stores}

Increased adiposity may be favourable for patients on haemodialysis providing an anti inflammatory benefit during times of cellular stress. ${ }^{39-43}$ Studies have shown improved survival and a better quality of life of patients with a BMI $>25$ on haemodialysis. ${ }^{41-43}$

\section{Age and gender}

Additional file 2, supplementary figure 1 shows that younger patients reported fewer problems in the haemodialysis group in both male and female. A similar trend is seen in the normal population where younger patients report fewer problems. The changes of the aging process on organ function may account for these findings. A study that looked at patients on haemodialysis showed improved quality of life in younger patients. ${ }^{44}$ Older female patients on peritoneal dialysis reported fewer problems that those in the younger age groups while the extremes of age among male peritoneal dialysis patients reported more problems. Male transplant recipients in the 18 to 24 years group and $45-54$ years group reported more problems. A future study for reasons for this trend should be considered.

\section{Social factors Employment}

Employment status significantly influenced quality of life. The majority of the employed population on renal replacement were transplant recipients followed by patients on peritoneal dialysis (Table 2). It is possible that patients receiving transplants were able to take advantage of employment opportunities because of more time availability. Transplant recipients followed by patients on peritoneal dialysis were able to obtain or continue their previous form of employment after commencing these modes of renal replacement therapy. In Canada, in the first 2 years after renal replacement therapy, employment opportunities was the best in the transplant subset. ${ }^{10}$ Table 2 also shows that in the occupation category of managers and professionals, transplant recipients formed the majority of these categories followed by patients on haemodialysis.

\section{Economic status}

Like employment, income is another factor affecting quality of life of patients receiving renal replacement therapy. This was also seen in another study by Alvares and colleagues. ${ }^{8}$ In this population, patients 
earning more than $\$ 4000$ Trinidad and Tobago dollars monthly (equivalent to approx. 600 US Dollars) had better mean quality of life scores.

\section{Renal replacement therapy options}

Options for renal replacement therapy include renal transplantation, peritoneal dialysis and haemodialysis. Similar to worldwide health care systems, each mode of therapy has specific requirements and criteria before initiation, some being more rigorous than others.

Haemodialysis in our population is associated with the poorest quality of life and the most problems reported by patients using the KDQOL-36 and EQ5D-3L questionnaires respectively. The 17 VAS points difference and 0.12 utility for patients on haemodialysis compared to peritoneal dialysis suggests that a transition to peritoneal dialysis can significantly affect health status. This also means that the choice of renal replacement therapy ultimately influences quality of life.

Certain modes of renal replacement therapy in our setting is associated with multiple checkpoints and prerequisites that should be satisfied, greater engagement of patients and their families and better support systems. As a result, these modalities of therapy like renal transplantation and peritoneal dialysis produce patients that are more likely to adhere to therapy and management of comorbidities. Table 9 demonstrates the requirements and factors implicated in this study for each modality of renal replacement therapy in our population.

Table 9: Factors implicated in the initiation of renal replacement therapy 


\begin{tabular}{|c|c|c|c|}
\hline \multirow{2}{*}{$\begin{array}{l}\text { Factors implicated in } \\
\text { therapy }\end{array}$} & \multicolumn{3}{|l|}{ Mode of therapy (chronic setting) } \\
\hline & Haemodialysis & Peritoneal dialysis & Renal transplant \\
\hline Government funding & Yes & Yes & Yes \\
\hline $\begin{array}{l}\text { Multidisciplinary } \\
\text { approach }\end{array}$ & Minimal & Minimal & $\begin{array}{l}\text { Management of comorbidities } \\
\text { by respective specialists }\end{array}$ \\
\hline Social support & $\begin{array}{l}\text { Medical social worker evaluates } \\
\text { socioeconomic status to qualify for } \\
\text { government funding }\end{array}$ & $\begin{array}{l}\text { Multiple medical social worker } \\
\text { evaluations }\end{array}$ & $\begin{array}{l}\text { Multiple medical social worker } \\
\text { evaluations and psychiatric } \\
\text { evaluations }\end{array}$ \\
\hline $\begin{array}{l}\text { Evaluation of home and } \\
\text { surroundings }\end{array}$ & Not required & $\begin{array}{l}\text { Required as therapy is done at } \\
\text { home }\end{array}$ & Not required \\
\hline Family integration & $\begin{array}{l}\text { Minimal- interaction with patient and } \\
\text { haemodialysis nurses }\end{array}$ & $\begin{array}{l}\text { Yes- adequate family meetings with } \\
\text { social worker and peritoneal dialysis } \\
\text { nurses }\end{array}$ & $\begin{array}{l}\text { Yes-multiple family meetings } \\
\text { with social worker and } \\
\text { transplant unit }\end{array}$ \\
\hline Counselling on therapy & Counselling by haemodialysis nurse & $\begin{array}{l}\text { Counselling by peritoneal dialysis } \\
\text { nurse }\end{array}$ & $\begin{array}{l}\text { Educational lectures pre and } \\
\text { post-transplant by transplant } \\
\text { coordinators } \\
\text { Counselling by multidisciplinary } \\
\text { team }\end{array}$ \\
\hline Ethical assessment & Not required & Not required & Required \\
\hline $\begin{array}{l}\text { Minimal time interval to } \\
\text { initiate therapy (state } \\
\text { funded) }\end{array}$ & $1-3$ months & 3-6 months & 6 months -1 year \\
\hline
\end{tabular}

\section{Limitations}

The quality of life and health state of patients who were diagnosed with end stage renal disease and do not wish for renal replacement therapy can be analysed as a further sub group. Renal clearances during peritoneal dialysis and haemodialysis can be investigated in further studies as this will establish the efficiency of dialysis for patients. Quality of life of the normal population and patients receiving transplants is another potential area of further study.

\section{Policy implication}


This study should guide policies to improve quality of life of persons on renal replacement therapy. Prevention of chronic kidney disease and other lifestyle diseases in this population should be priority in healthcare. A fistula first effort for all patients on haemodialysis should be the gold standard and early fistula or graft protocols in all centres should be implemented.

Improved psychosocial support networks for dialysis patients and educational programmes for patients and families when deciding choice of renal replacement therapy should be introduced.

Haemodialysis centres require revision of protocols and strict adherence to guidelines to reduce catheter related bloodstream infections. Auditing at dialysis centres with strict quality control can be increased to focus on the issues patients encounter. Performing quality of life assessments for patients on renal replacement therapy in all centres can be instituted to improve care and compare treatment in an aim to prolong survival. In other settings, patient reported outcome measurements use the KDQOL among other questionnaires for internal quality improvement activities. ${ }^{45}$

The institution of policies for patients to be commenced on peritoneal dialysis once they are eligible instead of haemodialysis would significantly improve the health and quality of life of these patients. Early identification of haemodialysis patients who are suitable for peritoneal dialysis can greatly contribute to better quality of life within this setting where a small percentage of patients on renal replacement therapy receive transplants. The transplantation unit in our setting is state funded and requires a nephrologist referral. Furthermore, the centre performs at most 2 live donor transplants per month. In this developing country, an enhanced renal transplantation and peritoneal dialysis service would improve health related quality of life among patients with end stage renal disease.

\section{Conclusions}

This study on quality of life and health state is the first in the Caribbean for patients on renal replacement therapy. With quality of life and state of health being invaluable measures of treatment outcome and the greater need for life saving therapy for patients diagnosed with end stage renal disease, this research should impact on the allocation of resources for chronic kidney disease patients. More importantly, it should influence the prevention and management of lifestyle diseases in this population.

\section{Abbreviations}

AVF/G-Arteriovenous fistula/graft

BMI-Body mass index

CCl-Charlson's Comorbidity Index

EQ-5D-3L-EuroQol

EQ-VAS-EuroQol Visual Analogue Scale 
HD-Haemodialysis

KDQOL-Kidney Disease Quality of Life

KTQ-Kidney Transplant Questionnaire

PD-Peritoneal Dialysis

T-Transplant

TT-Trinidad and Tobago

VAS-Visual Analogue Scale

\section{Declarations}

Ethics approval and consent to participate

Informed consent-Written consent to collect and use information was obtained from all participants in this study. The University of the West Indies Ethics Committee approved the form used to acquire the written consent.

The University of the West Indies Faculty of Medical Sciences Campus Ethics Committee

Approval: CEC007/09/15

South West Regional Health Authority Office of the Director of Health Research Committee

North West Regional Health Authority Ethics Committee

Eastern Regional Health Authority Research Committee

Tobago Regional Health Authority Research Committee

Consent for publication- not applicable

\section{Availability of data and materials}

The datasets used and/or analysed during the current study are available from the corresponding author on reasonable request. Most data generated or analysed during this study are included in this published article and its supplementary information files.

\section{Competing interests}

The authors declare that they have no competing interests

\section{Funding}


This research did not receive any specific grant from funding agencies in the public, commercial, or notfor-profit sectors.

\section{Authors' contributions}

Study design: SS, ST, RA, HB and GL. Data acquisition and interpretation: SS, GL, HB, ST and RA. Data analysis and statistical analysis: GL, HB, RA, ST and SS. Supervision: ST and HB. All authors have full access to the data in this study. HB and ST had final responsibility for the decision to submit the publication. Each author contributed intellectually to this study during drafting, revision and final version and all fully accept accountability for the work in this research.

\section{Acknowledgements}

Not applicable

\section{References}

1. Liem YS, Bosch JL, Arends LR. Quality of life assessed with the medical outcomes study short-form 36-Item health survey of patients on renal replacement therapy: a systematic review and metaanalysis. Value in Health. 2007; 10:390-97.

2. Cameron JI, Whiteside C, Katz J, Devins GM. Differences in quality of life across renal replacement therapies: a meta-analytic comparison. American Journal of Kidney Disease.2000; 35:629-37.

3. Makkar V, Kumar M, Mahajan R, Khaira NS. Comparison of outcomes and quality of life between hemodialysis and peritoneal dialysis patients in Indian ESRD population. Journal of Clinical and Diagnostic Research. 2015; 9:28-31.

4. Mendes de Abreu M, Walker DR, Sesso RC, Ferraz MB. Health-related quality of life of patients receiving hemodialysis and peritoneal dialysis in São Paulo, Brazil: a longitudinal study. Value in Health. 2011; 13:191-211.

5. García-Llana H, Remor E, Selgas R. Adherence to treatment, emotional state and quality of life in patients with end-stage renal disease undergoing dialysis. Psicothema. 2013; 25:79-86.

6. Bakewell AB, Higgins RM, Edmunds ME. Quality of life in peritoneal dialysis patients: decline over time and association with clinical outcomes. Kidney International Journal.2002; 61: 239-48.

7. Fiebiger W, Mitterbauer C, Oberbauer R. Health-related quality of life outcomes after kidney transplantation. Health Related Quality of Life Outcomes. 2004; 2:2. doi: 10.1186/1477-7525-2-2.

8. Alvares J, Cesar CC, Acurcio Fde A, Andrade El, Cherchiglia ML. Quality of life of patients on renal replacement therapy in Brazil: comparison of treatment modalities. Quality of Life Research Journal. 2012; 21:983-91.

9. Laupacis A, Keown P, Pus N, Krueger H, Ferguson B, Wong C, et al. A study of the quality of life and cost utility of renal transplantation. See comment in PubMed Commons belowKidney International Journal. 1996; 50:235-42. 
10. 10.Oliveira de Mendonça AE, Torres G, Salvetti M, Alchieri JC, Costa IKF. Changes in quality of life after kidney transplantation and related factors. Acta Paulista de Enfermagem. 2014; 27:287-92.

11. Eduardo N, Rodrigues, R, Barata C. Dyadic relationship and quality of life of patients with chronic kidney disease. Brazilian Journal of Nephrology. 2015; 37:315-22.

12. Liem YS, Bosch JL, Hunink MG. Preference based quality of life of patients on renal replacement therapy: a systematic review and meta-analysis. Value in Health. 2008; 11:733-41.

13. Panagopoulou A, Hardalias A, Berati S, Fourtounas C. Psychosocial issues and quality of life in patients on renal replacement therapy. Saudi Journal of Kidney Disease and Transplantation. 2009; 20:212-8.

14. Valderrabano F, Jofre R, Lopez-Gomez, JM. Quality of life in end stage renal disease patients. American Journal of Kidney Disease. 2001; 38:443-64.

15. Sayin A, Mutluay R, Sindel S. Quality of life in haemodialysis, peritoneal dialysis and transplantation patients. Transplant Proceedings. 2007; 39:3047-53.

16. Khan S, Bisnath R, Jaipaul J, Doodhai J, Ramlal D, Boodram S, et al. Screening for chronic kidney disease in East Trinidad using the National Kidney Foundation guidelines. https://www.semanticscholar.org.2015.

17. Soyibo AK, Barton EN. Report from the Caribbean Renal Registry. West Indian Medical Journal. 2007; 56:355.

18. Roberts L, Ramsaroop K, Seemungal T. Survival outcomes in renal transplantation in Trinidad and Tobago: SORTTT study. West Indian Medical Journal. 2012; 61:422-8.

19. International Standard Classification of Occupations of the United Nations. ISCO 08. 2010. www.ilo.org/public/english/bureau/stat/isco. Accessed 16 Nov 2019.

20. World Health Organization. Global Database on Body Mass Index: an interactive surveillance tool for monitoring nutrition transition. who.int/bmi/index. 2008. Accessed 16 Nov 2019.

21. World Health Organization. International Classification of Diseases and Related Health Problems. ICD 10.2016. www.who.int/classifications/icd/ICD10Volume2,Version 2016. Accessed 16 July 2019.

22. Tillin T, Sattar N, Godsland IF, Hughes AD, Chaturvedi N, Forouhi NG. Ethnicity specific obesity cutpoints in the development of type 2 diabetes mellitus-a prospective study including three ethnic groups in the United Kingdom. Diabetic Medicine. 2015; 32:226-34.

23. Charlson ME, Pompei P, Ales KL, MacKenzie CR. A new method of classifying prognostic comorbidity in longitudinal studies: development and validation. J Chronic Dis. 1987; 40:373-83.

24. Bakewell AB, Higgins RM, Edmunds ME. Does ethnicity influence perceived quality of life of patients on dialysis and following renal transplant? Nephrology Dialysis Transplantation. 2001; 16:13951401.

25. Yee Chow SK, Ling Tam BM. Is the kidney disease quality of life-36(KDQOL-36) a valid instrument for Chinese dialysis patients? Bio Med Central Nephrology. 2014; 15:199. 
26. Chen JY, Choi EPH, Wan EYF, Chan AKC, Tsang JPY, Chan KHY, et al. Validation of the disease specific components of the Kidney Disease Quality of Life-36(KD-QOL 36) in Chinese dialysis patients undergoing maintenance dialysis. Public Library of Science One Journal. 2016; 11: e0155188. doi: 10.1371/journal.pone.0155188.

27. Ricardo AC, Hacker E, Lora CM, Ackerson L, DeSalvo KB, Go A, et al. Validation of the kidney disease quality of life-36 short form 36 (KDQOL-36) US Spanish and English versions in a Cohort of Hispanics with chronic kidney disease. Ethnicity and Disease. 2013; 23:202-9.

28. Kurella M, Luan J, Yaffe K, Chertow GM. Validation of the kidney disease quality of life (KDQOL) cognitive function subscale. Kidney International Journal. 2004; 66:2361-7.

29. Bailey H, Stolk E, Kind P. Toward explicit prioritization for the Caribbean: An EQ-5D value set for Trinidad and Tobago. Value in Health. 2016; 11:60-7.

30. Tayyebi A, Raiesifar A, Mehri SN, Ebadi A, Einolahi B, Pashandi S. Measuring health related quality of life in renal transplant patients: psychometric properties and cross cultural adaptation of the kidney transplant questionnaire in Persian. Nephro-Urology. 2012; 4:617-21.

31. Wilson B, Cleary PD. Linking clinical variables with health related quality of life. Journal of the American Medical Association. 1995; 273:59-64.

32. Robinson BM, Akizawa T, Jager KI, Kerr PG, Saran R, Pisoni RL. Factors affecting outcomes in patients reaching end stage kidney disease worldwide: differences in access to renal replacement therapy, modality use, and haemodialysis practices. Lancet. 2016; 388:294-306.

33. Evans RW, Manninen L, Garrison LP, Hart LG, Blagg CR, Gutman RA, et al. The quality of life of patients with end stage renal disease. New England Journal of Medicine. 1985; 312:553-59.

34. Rabbat CG, Thorpe KE, Russell JD, Churchill DN. Comparison of Mortality Risk for Dialysis Patients and Cadaveric First Renal Transplant Recipients in Ontario, Canada. Clinical Journal of the American Society of Nephrology. 2000; 11:5917-22.

35. Don YK, Tammy KC, Myoung-Hee K, Noh J, Kim G, Kim H, et al. Superior outcomes of kidney transplantation compared with dialysis: An optimal matched analysis of a national population-based cohort study between 2005 and 2008 in Korea. Medicine. 2016; 95:4352. doi:10.1097/MD.0000000000004352.

36. Francisco ALM, Fresnedo GF, Palomar R, Pinera C, Arias M. The renal benefit of a healthy lifestyle. Kidney International Journal. 2005; 69:52-6.

37. Chen MC, Tsai WL, Tsai IC, Chan SW, LiaoWC, Lin PC et al. Arteriovenous fistula and graft evaluation in hemodialysis patients using MDCT: a primer. American Journal of Roentgenology. 2010; 194:83847.

38. Wasse $\mathrm{H}$, Kutner N, Zhang R, Huang Y. Association of initial HD vascular access with patient reported health status and quality of life. Clinical Journal of the American Society of Nephrology. 2007; 2:70871.

39. Mohamed-Ali V, Goodrick S, Bulmer K, Holly JM, Yudkin JS, Coppack SW. Production of soluble tumor necrosis factor receptors by human subcutaneous adipose tissue in vivo. American Journal of 
Physiology. 1999; 277:971-75.

40. Demas GE, Drazen DL, Nelson RJ. Reductions in total body fat decrease humoral immunity. Proceedings of the Royal Society Biological Sciences. 2003; 270: 905-11.

41. Beddhu S. The body mass index paradox and an obesity, inflammation, and atherosclerosis syndrome in chronic kidney disease. Seminar in Dialysis Journal. 2004; 17:229-32.

42. Kalantar-Zadeh K, Abbott KC, Salahudeen AK, Kilpatrick RD, Horwich TB. Survival advantages of obesity in dialysis patients. The American Journal of Clinical Nutrition. 2005; 81:543-54.

43. Ikizler TA. Resolved: Being fat is good for dialysis patients: The Godzilla Effect. Journal of the American Society of Nephrology. 2008; 19:1059-64.

44. Gerasimoula K, Lefkothea L, Maria L, Victoria A, Paraskevc T, Maria P. Quality of life in haemodialysis patients. Materia Sociomedica. 2005; 27:305-9.

45. Peipert JD, Hays RD. Using patient reported measures in dialysis clinics. Journal of the American Society of Nephrology. 2017; 12:1889-91. doi:10.2215/CJN.02250217.

\section{Figures}

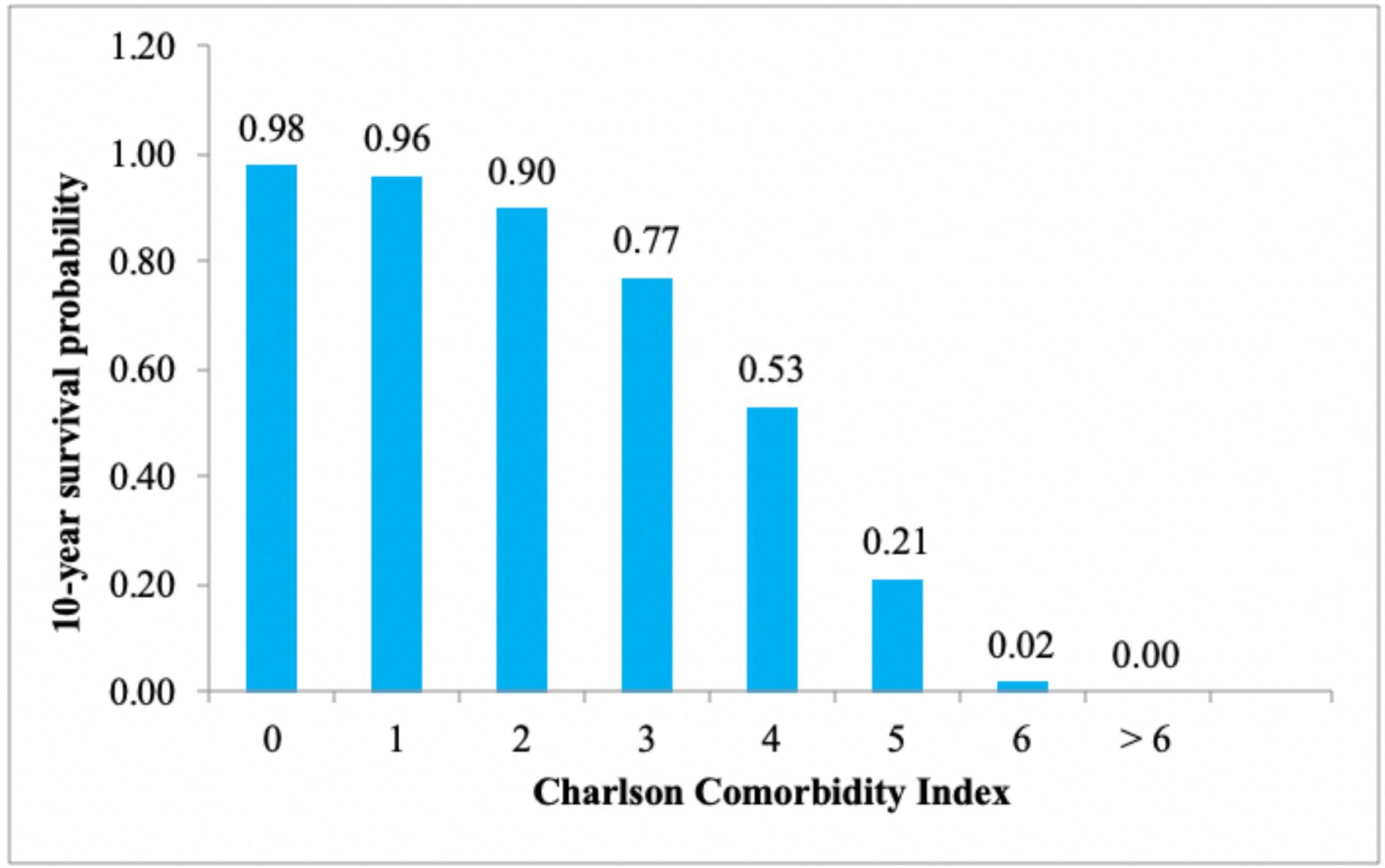

Figure 1

Charlson's comorbidity index and 10-year survival 


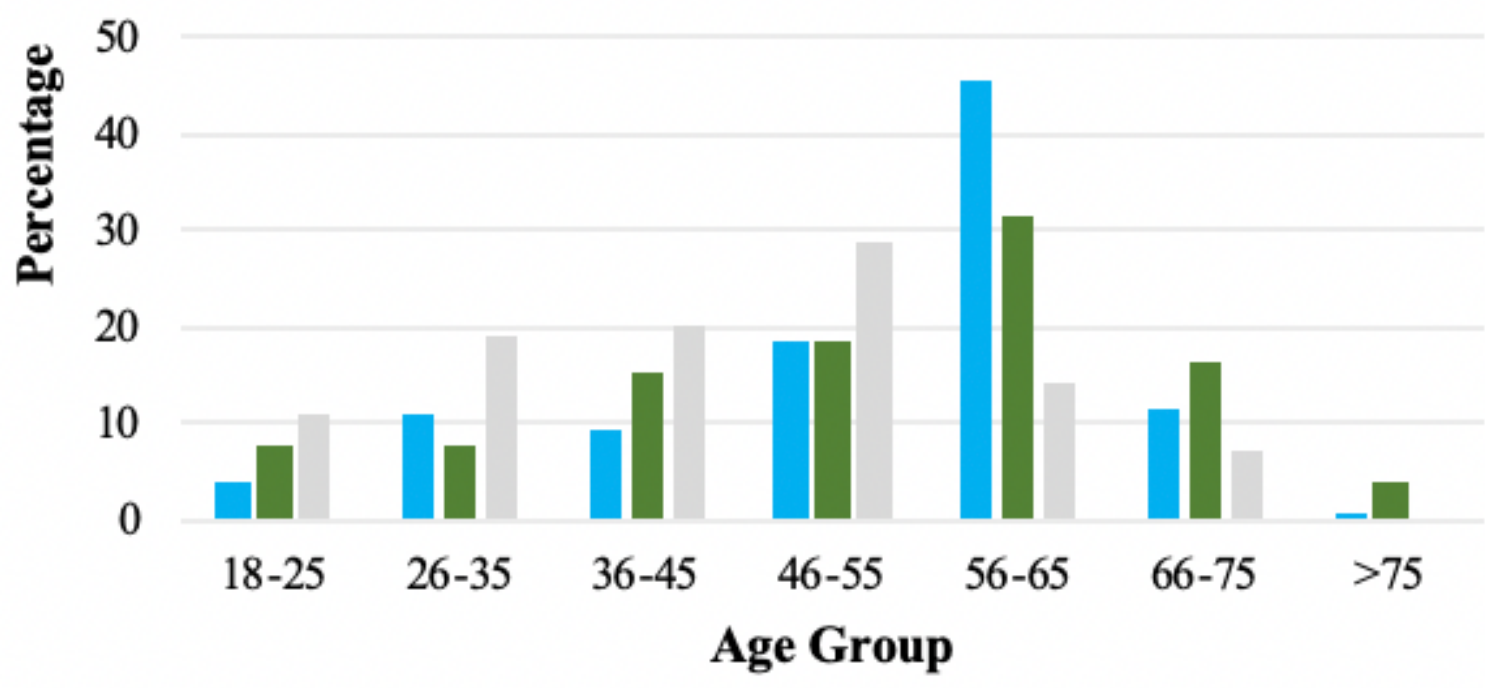

Haemodialysis $\quad$ Peritoneal $\square$ Transplant

Figure 2

Age groups of patients on renal replacement therapy

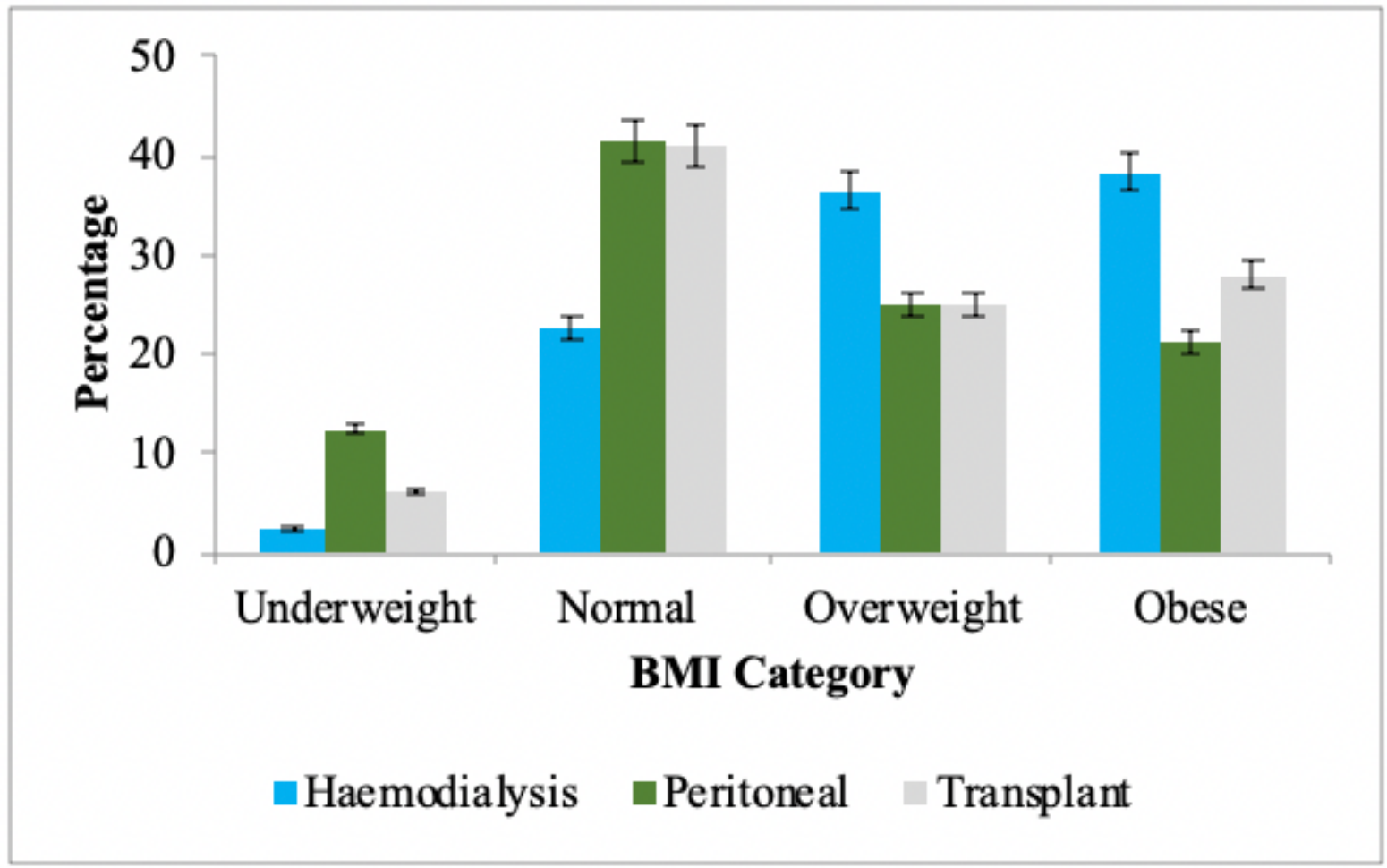

Figure 3

Body Mass Index (BMI) category and mode of therapy 


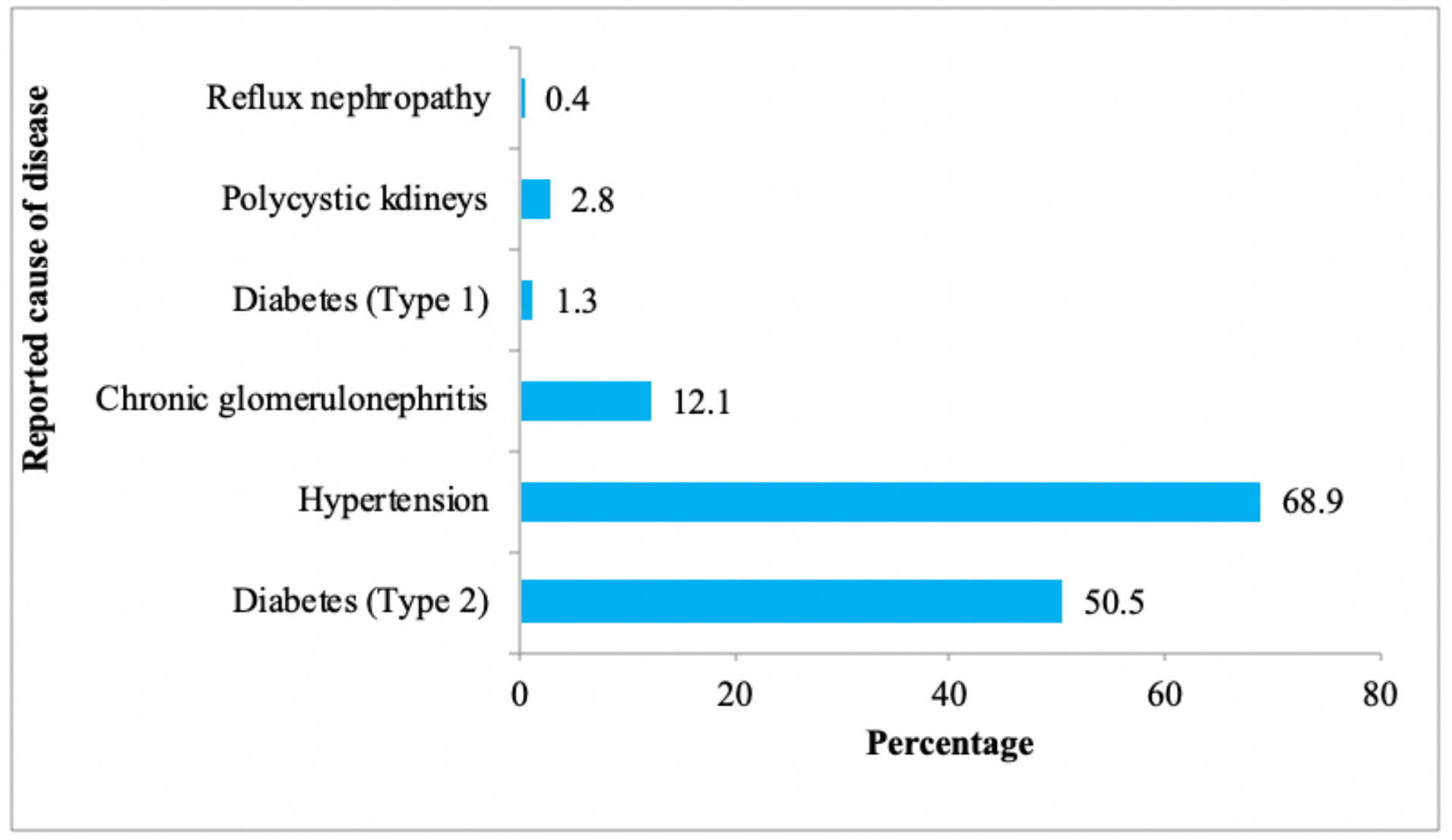

Figure 4

Self-reported cause of kidney disease

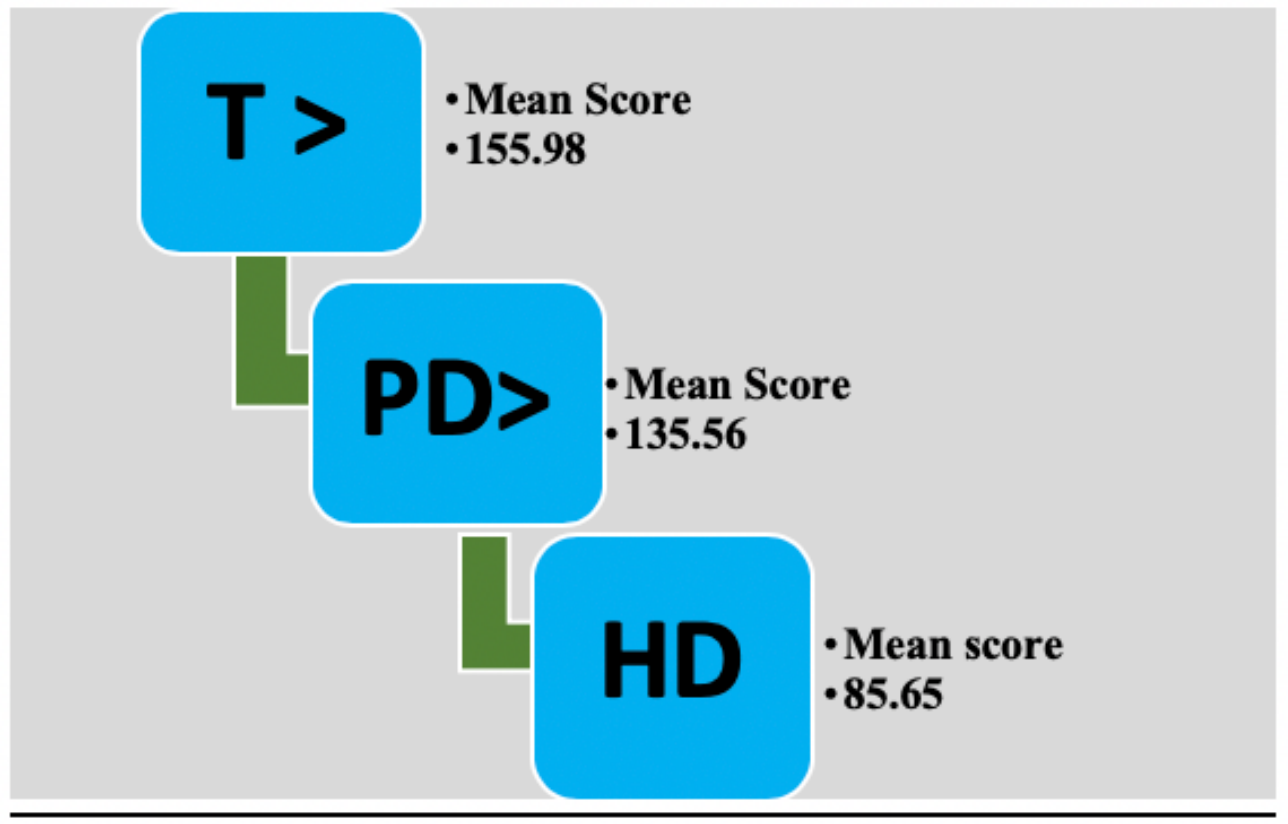

HD-haemodialysis, PD-peritoneal dialysis, T-renal transplantation, AVF/G-arteriovenous fistula or graft 
Mean KDQOL total scores and mode of therapy

\section{Supplementary Files}

This is a list of supplementary files associated with this preprint. Click to download.

- Additionalfile2supplementaryfigure1.docx

- Additionalfile1supplementarytable1.xlsx 